\title{
ATIVIDADE INSETICIDA DE Nicotiana tabacum E Azadirachta indica SOBRE Helicoverpa armigera Hübner,1908 (Lepidoptera:Noctuidae)
}

\author{
Cristhian Eliseo Durán Aguirre ${ }^{1}$ \\ Luis Moreira de Araujo Junior ${ }^{2}$ \\ Débora Ferreira Melo Fragoso ${ }^{3}$ \\ Julielson de Oliveira Ataíde ${ }^{4}$ \\ Ana Clara Thezolin Acevedo 5 \\ Sabrina Buqueroni ${ }^{6}$ \\ Dirceu Pratissoli ${ }^{7}$
}

Resumo: A mariposa Helicoverpa armigera Hübner,1908 (Lepidoptera:Noctuidae), mais conhecida como lagarta-do-algodoeiro, quando atingi o nível de controle passa a ser uma praga agressiva e de rápido crescimento populacional. O principal método de controle tem sido por meio de inseticidas químicos sintéticos, cujo efeito pode ser comprometido pelo desenvolvimento de populações resistentes da praga. No intuito de propiciar uma alternativa no manejo da praga em questão, objetivou-se avaliar a atividade inseticida de extratos vegetais em lagartas de primeiro instar de $\mathrm{H}$. armigera. Com isto, avaliou-se a toxicidade aguda dos extratos vegetais, pela contagem de lagartas mortas após 72 horas de tratadas. Os extratos vegetais de Nicotiana tabacum e Azadirachta indica apresentaram mortalidade de 11,31 e 16,80\% respectivamente, diferindo estatisticamente. Logo, o produto que apresentou maior valor de mortalidade foi o extrato de $A$. indica.

Palavras-chaves: Controle biológico; Inseticidas botânicos; Mortalidade.

\footnotetext{
1 Pós-graduação em Produção vegetal/UFES, Brasil. E-mail: cduran-21@hotmail.com.

2 Pós-graduação em Produção vegetal/UFES, Brasil. E-mail: luisjrmoreira@gmail.com.

3 Pós-graduação em Produção vegetal/UFES, Brasil. E-mail: debmelo@gmail.com.

4 Graduação em Agronomia/UFES, Brasil. E-mail: julielsonoliveira@hotmail.com.

5 Graduação em Agronomia/UFES, Brasil. E-mail: clarathezolin@hotmail.com.

${ }^{6}$ Graduação em Agronomia/UFES, Brasil. E-mail: sabrinabuqueroni21@gmail.com.

7 Diretor Pós-graduação em Produção vegetal/UFES, Brasil. E-mail: dirceu.pratissoli@gmail.com.
} 